\title{
USO Y ABUSO DE LA PRISIÓN PREVENTIVA EN EL PROCESO PENAL PERUANO
}

\author{
JOAQUín MISSIEGO DEL SOLAR* \\ Universidad de Lima, Lima, Perú \\ Recibido: 24/1/2020 Aceptado: 1/2/2020 \\ doi: https://doi.org/10.26439/iusetpraxis2021.n053.5073
}

\begin{abstract}
RESUMEN. El presente artículo muestra la preocupación existente, a pesar de los esfuerzos de la Corte Suprema, por la variada interpretación sobre los diferentes criterios que existen para la aplicación de la prisión preventiva en el desarrollo de los procesos penales en nuestro país. Asimismo, por la inseguridad jurídica que nace como consecuencia de la ausencia de un criterio uniforme de parte de las autoridades al momento de solicitar o imponer dicha medida.
\end{abstract}

PALABRAS CLAVE: prisión / prisión preventiva / medida cautelar

\section{USE AND ABUSE OF PREVENTIVE DETENTION IN THE PERUVIAN CRIMINAL PROCESS}

ABSTRACT. This article shows the existing concert, despite the efforts of the Supreme Court, for the varied interpretations of the different criteria for the application of preventive detention in the development of criminal proceedings in our country and the legal uncertainty that arises as a consequence of the absence of a uniform criteria from our authorities while requesting the said measure.

KEYWORDS: prison / preventive prison / caution measure

\footnotetext{
* Abogado por la Universidad de Lima. Profesor en la misma casa de estudios. Miembro del Consejo Consultivo de la revista Advocatus.
} 


\section{INTRODUCCIÓN}

El ser humano por naturaleza es un ser libre. Esa libertad tiene distintas formas y manifestaciones: se presenta como la libertad de pensamiento, opinión, expresión, religión, asociación y tránsito, entre otras. En virtud de su vital importancia como derecho humano, la libertad en todas sus formas debe ser objeto de cuidado y protección por parte del Estado; sin embargo, cuando el ciudadano abusa de su libertad en perjuicio de otros ciudadanos y se vuelve un peligro para sus pares, para la sociedad, por el hecho de cometer un delito grave, el Estado se ve obligado a tomar medidas drásticas que, en algunos casos, traen consigo la pérdida de la libertad y la orden de reclusión en un penal.

En este sentido, es importante analizar si el Estado, a través de los órganos jurisdiccionales competentes, ha venido usando o abusando de la prisión preventiva en nuestro país.

\section{PRISIÓN PREVENTIVA}

Hoy en día, la finalidad de un proceso penal es determinar si la persona imputada de la comisión de un hecho delictivo es o no responsable penalmente de los cargos formulados en su contra.

La antigua corriente que consignaba la sanción como finalidad del proceso penal ha quedado rezagada, y en un mundo como el actual, donde se busca con mayor insistencia el respeto a los derechos y garantías de las personas, es imposible pensar que un proceso se inicia con el fin de castigar. El castigo (la pena) será consecuencia de una serie de actos de investigación y juzgamiento, en los cuales la persona imputada tendrá la oportunidad de conocer los cargos en su contra, defenderse, ser asesorado por un abogado, gozar de un plazo razonable, presentar pruebas de descargo, contar con la presencia de un juez imparcial, entre otros aspectos, que se resumen en dos conceptos:

- Presunción de inocencia

- Debido proceso

De acuerdo con el artículo 2, inciso 24e), de la Constitución Política del Perú: “Toda persona es considerada inocente mientras no se haya declarado judicialmente su responsabilidad". A su vez, el artículo 139 , inciso 3 , señala que uno de los principios y derechos de la función jurisdiccional es "la observancia del debido proceso [...]".

En esa línea, estas garantías son la base de un juicio justo en el que la condena o absolución estará condicionada al cumplimiento legal de los procedimientos que conduzcan a una decisión jurisdiccional. Esto trae consigo, hacia el interior, la llamada seguridad jurídica; y, hacia el exterior, es decir, hacia la comunidad, la seguridad y tranquilidad social. Sin embargo, antes de llegar a un pronunciamiento final, esto es, a una sentencia, se hace necesario cuidar (cautelar) el proceso, y para ello existen justamente 
las medidas cautelares personales y las reales, cuya finalidad principal es garantizar el normal desarrollo del proceso.

Las medidas cautelares personales, como su nombre lo indica, se dictan sobre el sujeto, sobre la persona natural, y tienen por objeto garantizar la presencia del imputado durante el proceso con la finalidad de que este se encuentre presente durante el desarrollo del mismo. En cambio, las medidas cautelares de índole real buscan garantizar el eventual pago de una reparación civil en favor de la víctima o agraviado del delito, en caso de que se acredite la existencia de daño en función de los hechos. También tienen el fin de garantizar la conservación de documentos u otro material probatorio que sea útil para su evaluación en el esclarecimiento de los hechos.

Un mandato de prisión preventiva implica la pérdida de la libertad ambulatoria de una persona que se encuentra inmersa en un proceso penal, en el cual se está decidiendo si es o no responsable penalmente de los hechos por los cuales, según el estado en que se encuentre el proceso, se le investiga, acusa o juzga. Esto quiere decir que, al momento de dictarse la medida, la persona no tiene una sentencia condenatoria en su contra. A su vez, dicho mandato trae consigo que el sujeto sea internado en un penal, por un plazo determinado, mientras se resuelve su situación jurídica en el proceso.

El derecho a la libertad física se encuentra consagrado en el artículo 2, inciso 24f), de la Constitución Política del Perú, el cual señala: “Nadie puede ser detenido sino por mandamiento escrito y motivado del juez o por las autoridades policiales en caso de flagrante delito". De acuerdo con la propia Constitución, cuando se produce una detención en flagrancia, esta puede durar un máximo de 48 horas. El sujeto puede recuperar su libertad mientras es objeto de investigación, o si el fiscal considera que es necesaria una medida gravosa, deberá solicitarse al juez penal.

Como se puede apreciar, solo el juez penal puede dictar un mandato de prisión preventiva; y el procedimiento y las condiciones que deben darse para que tome tal decisión se encuentran a partir del artículo 268 del nuevo Código Procesal Penal, que prescribe lo siguiente:

El juez, a solicitud del Ministerio Público, podrá dictar mandato de prisión preventiva, si atendiendo a los primeros recaudos sea posible determinar la concurrencia de los siguientes presupuestos:

a) Que existen fundados y graves elementos de convicción para estimar razonablemente la comisión de un delito que vincule al imputado como autor o partícipe del mismo.

b) Que la sanción a imponerse sea superior a cuatro años de pena privativa de libertad; $y$

c) Que el imputado, en razón a sus antecedentes y otras circunstancias del caso particular, permita colegir razonablemente que tratará de eludir la acción de la 
justicia (peligro de fuga) u obstaculizar la averiguación de la verdad (peligro de obstaculización).

Respecto a este último requisito, en el que se concentra el llamado peligro procesal, el nuevo Código Procesal Penal, a diferencia del antiguo Código de Procedimientos Penales, nos presenta las pautas y parámetros que el juez debe tener en cuenta cuando se habla de peligro de fuga o peligro de obstaculización. Con ello, la intención del legislador era evitar que el juez - como sucedía con el Código anterior - interpretase a su criterio o libre albedrío estas dos situaciones y se pudiera encontrar situaciones similares con fundamentaciones completamente distintas. En este sentido, el artículo 269 del nuevo Código Procesal Penal prescribe:

Para calificar el peligro de fuga, el juez tendrá en cuenta:

1. El arraigo en el país del imputado, determinado por el domicilio, residencia habitual, asiento de la familia y de sus negocios o trabajo y las facilidades para abandonar definitivamente el país o permanecer oculto;

2. La gravedad de la pena que se espera como resultado del procedimiento;

3. La magnitud del daño causado y la ausencia de una actitud voluntaria del imputado para repararlo;

4. El comportamiento del imputado durante el procedimiento o en otro procedimiento anterior, en la medida que indique su voluntad de someterse a la persecución penal; y

5. La pertenencia del imputado a una organización criminal o su reintegración a las mismas.

En lo que se refiere al peligro de obstaculización, el artículo 270 del nuevo Código Procesal Penal señala:

Para calificar el peligro de obstaculización se tendrá en cuenta el riesgo razonable de que el imputado:

1. Destruirá, modificará, ocultará, suprimirá o falsificará elementos de prueba.

2. Influirá para que coimputados, testigos o peritos informen falsamente o se comporten de manera desleal o reticente.

3. Inducirá a otros a realizar tales comportamientos.

Sin embargo, pese a que en el nuevo Código Procesal Penal se indican los requisitos para considerar el peligro de fuga u obstaculización, los jueces siguieron utilizando criterios diferentes para la consideración de estos factores, quedando en muchos casos la suerte del procesado no condicionada a los requisitos procesales, sino al juez que le tocaba conocer el pedido de prisión preventiva. Por tal motivo, fue necesario que los 
jueces supremos se reuniesen y fijasen los criterios que debían aplicarse para la imposición de una medida tan grave como lo es la prisión preventiva. Con este fin se llevó a cabo el Acuerdo Plenario 1-2019/CIJ-116, que a continuación pasamos a explicar.

\section{ACUERDO PLENARIO 1-2019/CIJ-116}

El Acuerdo Plenario 1-2019/CIJ-116, del 10 de septiembre del 2019, nos recuerda los requisitos que debe tener en cuenta el juez al momento de dictar un mandato de prisión preventiva.

Intencionalmente escribo "nos recuerda" porque, como lo he señalado, el nuevo Código Procesal Penal ya nos indicaba los criterios y pautas para que pudiera expedirse un mandato de prisión preventiva; sin embargo, muchos jueces tenían una particular interpretación de los artículos 269 y 270 del citado Código, lo cual traía consigo la expedición en un primer momento de mandatos de prisión preventiva que meses después era revocados, en gran parte de los casos, por la Sala Penal, a raíz de que se consideraba que los fundamentos empleados por el juez penal no habían sido los adecuados. Inclusive en algunos casos fue necesario llegar hasta instancias constitucionales, en las cuales la intervención del Tribunal Constitucional expresaba en sus sentencias que se habían impuesto medidas de restricción a la libertad personal que habían vulnerado garantías y derechos del imputado.

Entre otros aspectos, los jueces supremos dejan en claro en el Acuerdo Plenario 1-2019/CIJ-116 que para que se expida el mandato de prisión preventiva debe tenerse en cuenta las siguientes consideraciones:

\section{Con relación a la sospecha de la comisión de un delito}

Cuando la fiscalía solicita al juez la imposición de una medida cautelar personal como la prisión preventiva, no solo debe basarse en suposiciones o hipótesis sin respaldo probatorio suficiente que muestre, en principio, que nos encontramos frente a la comisión de un hecho delictivo. Frente a ello, el juez debe ponderar y verificar la presencia de suficientes elementos de convicción que generen bastantes elementos que motiven la existencia de sospecha sobre la comisión del delito materia de imputación y que, por tanto, traigan consigo una situación grave.

Es importante tener en cuenta que el pedido de prisión preventiva se realiza generalmente al inicio de la etapa de investigación preparatoria o en el transcurso de la misma; esto quiere decir que se vienen recolectando elementos de cargo y de descargo que permitirán al fiscal decidir si posteriormente, durante la etapa intermedia, presentará el requerimiento acusatorio. En tal sentido, el Acuerdo Plenario 1-2019/CIJ-116 señala que los jueces deberán encontrarse con un alto grado de convencimiento de la 
posibilidad de que el investigado sea posteriormente acusado y, por ende, sometido a juicio oral.

Los indicios servirán y serán muy útiles para poder llevar a cabo una investigación, pero no son suficientes para que se acepte un pedido de prisión preventiva. En resumen, a estas alturas, las pruebas deben generar en el juez el convencimiento de un alto grado de probabilidad de que nos encontramos frente a un delito.

\section{En lo que respecta a la prognosis de la pena}

En principio, para todos queda claro el mensaje que surge de la misma norma: que la sanción a imponerse sea superior a los cuatro años de pena privativa de libertad. De los tres requisitos materia de evaluación para la procedencia o no de la prisión preventiva, este resulta ser el más objetivo de ellos, y solo es necesario verificar el delito materia de imputación y la sanción que prevé el Código Penal en el caso particular.

Además de ello, la Corte Suprema recuerda que, si bien es cierto que se trata de un requisito para la imposición de la prisión preventiva, no es el único que se debe tomar en cuenta, ni tampoco el que sirva como única base o sustento para amparar y respaldar la medida cautelar que se podría imponer.

Ahora bien, cuando la probabilidad de sanción implica una pena alta o grave, aparece un supuesto que nos conduce al tercer requisito para dictar un mandato de prisión preventiva: el peligro procesal, en este caso particular, orientado hacia el llamado peligro de fuga.

\section{En lo que atañe al peligro procesal}

Esta figura debe entenderse en la posibilidad de la opción frente a dos elementos: el ya mencionado peligro de fuga y el entorpecimiento de la actividad probatoria. En este caso, basta que se acredite la presencia de uno de los dos presupuestos consignados para el peligro procesal, para que se tenga por cumplido este requisito.

En efecto, el Acuerdo Plenario 1-2019/CIJ-116 reafirma el hecho de que es suficiente con que se pueda acreditar uno de los dos: el peligro de fuga o, en todo caso, el peligro de entorpecimiento de la actividad probatoria. No es necesario que se confirme la presencia de ambos supuestos de manera simultánea. A lo señalado por la Corte Suprema cabe agregar lo ya mencionado anteriormente, en el sentido de que el legislador en el nuevo Código Procesal, a diferencia del Código de Procedimientos Penales, nos describe cuáles son los criterios para considerar la existencia ya sea del peligro de fuga o del peligro de entorpecimiento de la actividad probatoria, para no dejar a la interpretación, peligrosamente subjetiva, los criterios para la solicitud e imposición de la medida cautelar personal de prisión preventiva. 
En el acuerdo plenario aparecen algunas pautas que llevan a variar la forma de tratar este tema, con respecto a la forma en que era trabajado en el Código anterior. Como sabemos, antes no hablábamos de un mandato de prisión preventiva, sino de uno de detención, que en el fondo tiene el mismo sentido: internar en un penal a una persona sin sentencia, mientras se encuentra inmersa en un proceso penal. Tal es caso, por ejemplo, del peligro de fuga, que antiguamente se ponderaba con base en la intención que había tenido el sujeto de huir o alejarse del proceso; sin embargo, hoy en día es un factor importante independientemente de que el sujeto haya dado elementos para presumir una fuga, o tenga las posibilidades o los medios que podrían facilitarla.

También toma un lugar muy importante el arraigo, el cual vemos que viene siendo ponderado bajo distintos aspectos como el familiar, el laboral o el domiciliario, por ejemplo. Se puede apreciar casos en los que se consideraba la ausencia de arraigo domiciliario por el hecho de no tener una vivienda propia, sino alquilada. Sobre este tema es muy interesante la publicación del portal web LP. Pasión por el Derecho (2019), donde se señala que el fiscal doctor Roberto Carlos Reynaldi Román puso una publicación en su cuenta de Facebook en la que mencionaba hasta 18 tipos de arraigo. Un extracto del artículo en mención dice a la letra lo siguiente:

Los criterios relacionales [en palabras de la Corte Suprema] pueden ser diversos y no deben limitarse únicamente a tres [familiar, laboral y domiciliario] como sucede en la práctica del litigio. Un error cada vez más frecuente. El parámetro para medir la calidad del arraigo debe encontrarse en el criterio de dependencia. Tal concepto se refiere a la relación vinculante que tiene el sujeto respecto de los bienes, relaciones y actividades que sirven para juzgar su vida. (LP. Pasión por el Derecho, 2019, párr. 3)

El citado fiscal, además de los clásicos arraigos familiar, laboral y domiciliario, menciona y explica otras varias formas de arraigo, entre ellas: religioso, político, estudiantil, empresarial, sentimental, contractual, patrimonial, entre otros.

En cuanto al otro factor que se debe considerar en el peligro procesal, es decir, el peligro de entorpecimiento de la actividad probatoria, se refiere a la posibilidad del imputado de destruir, alterar u ocultar las pruebas que podrían servir para el esclarecimiento de los hechos, o el riesgo que podría generar el propio procesado frente a testigos, coinculpados, víctimas o cualquier otro sujeto procesal que podrían verse amenazados y, por consiguiente, no brindarían una declaración libre, espontánea, sin presiones ajenas, que los hiciesen no declarar la veracidad de la información que conocen con relación al caso que viene siendo objeto del proceso penal. El peligro deberá ser real y no una suposición o posibilidad. 


\section{Otros elementos importantes que surgen del Acuerdo Plenario 1-2019/CIJ-116}

Entre los aspectos que merecen ser resaltados, se encuentra el de la razonabilidad del tiempo de duración de las audiencias en las que el juez decidirá si acepta o no el requerimiento formulado por el Ministerio Público y, por tanto, si determina imponer la prisión preventiva al imputado. El citado acuerdo plenario señala que tanto el Ministerio Público como la defensa técnica del imputado deben enfrentar sus argumentos basándose en los aspectos centrales y principales que guarden relación con el tema materia de debate: la imposición o no de la medida de prisión preventiva, y es obligación del juez controlar los tiempos de intervención y participación de las partes, no dejando ni permitiendo que los sujetos procesales extiendan sus argumentos en maratónicas presentaciones y alegaciones, que muchas veces son totalmente lejanas de lo que debe constituir el elemento principal de debate.

Otro elemento importante fue dejar en claro qué es lo que se estaba discutiendo: en una audiencia sobre prisión preventiva, era si procedía o no el pedido formulado por el Ministerio Público para que la persona investigada sea internada en un penal por un plazo determinado, mientras el proceso se va desarrollando. En este caso, no se discute - ni era el momento para ello- si la persona es o no responsable penalmente de los hechos materia de imputación; tampoco, cuál es la pena que se aplicará al procesado. El mandato de prisión preventiva no debe entenderse ni mucho menos ser una condena anticipada.

Este último tema nos lleva a la razonabilidad del plazo de duración de la prisión preventiva en caso de que se dicte la medida. No es cuestión de que, porque la norma dice que el plazo máximo podrá ser de 9, 18 o 36 meses, según el caso, se decida directamente por el plazo máximo. La Corte Suprema deja un mensaje bastante claro en el Acuerdo Plenario 1-2019/CIJ-116: el plazo no puede estar condicionado a la velocidad o ritmo que pudiera desarrollar el Ministerio Público para llevar a cabo las investigaciones, sino que debe estar sustentado en criterios que pueden surgir de cada proceso en particular, como los siguientes:

- La dimensión y complejidad de la investigación

- La gravedad y extensión del delito imputado

- La dificultad y cantidad de los actos de investigación que se requieran

- La necesidad o no de realizar actos de cooperación judicial internacional

- La obligación de realizar actividades periciales complejas

- La presencia o ausencia, además del comportamiento procesal, de los imputados

- El riesgo de fuga y las posibilidades de riesgo de obstaculización 


\section{LA APLICACIÓN DE LA PRISIÓN PREVENTIVA EN LA ACTUALIDAD}

Existe, sin lugar a dudas, un factor coyuntural que nos ha cambiado la vida a todos: la emergencia sanitaria que nos toca vivir desde marzo del 2020 en nuestro país trajo consigo una serie de medidas que impactaron directamente en el día a día de toda la población.

El COVID-19 obligó a que se incorporase en la práctica un elemento que observamos en la teoría y que está referido a situaciones en las cuales la salud del imputado se ve expuesta a un riesgo que lo pudiese poner en grave peligro. A partir de ello comenzó a aparecer en las resoluciones judiciales con mayor frecuencia la llamada detención domiciliaria. En términos simples, procede la prisión domiciliaria cuando se cumplen los tres requisitos de la prisión preventiva, pero se presenta un factor extra justamente vinculado a la salud del sujeto que no hace recomendable su presencia física en un penal. Así pues, el artículo 290 del nuevo Código Procesal Penal prescribe en sus dos primeros incisos lo siguiente:

[...] se impondrá detención domiciliaria cuando, pese a corresponder prisión preventiva, el imputado:

a) Es mayor de 65 años de edad;

b) Adolece de una enfermedad grave o incurable;

c) Sufre grave incapacidad física permanente que afecte sensiblemente su capacidad de desplazamiento;

d) Es una madre gestante.

En todos los motivos previstos en el numeral anterior, la medida de detención domiciliaria está condicionada a que el peligro de fuga o de obstaculización pueda evitarse razonablemente con su imposición.

Sin embargo, la aplicación de esta medida en los últimos meses -y a raíz, reiteramos, de la grave situación y peligro a la salud en la cual nos encontramos actualmente-está motivando a dictar la detención domiciliaria no necesariamente por convicción, sino por necesidad, que obliga a valorar un elemento que no venía siendo muy tomado en cuenta antes de la pandemia, como es el factor de la salud.

Citaré como ejemplo un caso mediático en el que se otorgó, durante las primeras semanas de la declaratoria de emergencia sanitaria, la detención domiciliaria en función de aspectos vinculados a la salud personal, lo cual se produjo en el Expediente 00036-201748-5002-JR-PE-03, de fecha 30 de abril del 2020, expedido por la Primera Sala Penal de Apelaciones Nacional Permanente Especializada en Delitos de Corrupción de Funcionarios. En este caso, cabe resaltar las siguientes consideraciones de la Sala de Apelaciones: 
8.10 Estando a lo señalado por la $\mathrm{CIDH}$, se debe proceder con reevaluar casos de prisión preventiva para identificar aquellos que pueden ser convertidos en medidas alternativas a la privación de libertad, dando prioridad a las poblaciones con mayor riesgo de salud frente a un eventual contagio del COVID-19, principalmente las personas mayores y mujeres embarazadas o con hijos lactantes.

8.11 Se debe tener en claro que el riesgo de contagio de una pandemia como la que está ocasionando el COVID-19 en nuestro país y sus probables consecuencias han sido impredecibles [...].

8.12 [...] los probables efectos de la pandemia COVID-19 no pueden ser considerados como causales de cesación de prisión preventiva [...].

8.13 En ese sentido, el instituto procesal en el que pueda utilizarse razones de tipo humanitario para sustituir la prisión preventiva es la detención domiciliaria [...].

Entonces cabe nuevamente preguntarse: ¿los criterios de aplicación de la prisión preventiva hoy en día se originan en elementos de convicción u obligación? ¿Aquellas personas cuyas solicitudes de prisión preventiva derivaron en detenciones domiciliarias, u otras a las cuales se les varió el mandato inicial y fueron remitidas a sus domicilios, hubiesen tenido igual respuesta en situaciones ajenas a la actual? Finalmente, también es posible preguntarse: ¿por qué hay casos de personas que han pasado largos periodos de tiempo siendo investigadas bajo un mandato de prisión preventiva, pero a la fecha no son sometidas a juicio oral?

Personalmente, y ya lo he señalado en anteriores oportunidades, creo que el principal problema es que la prisión preventiva es aplicada sin tener en cuenta los elementos necesarios y suficientes para su imposición; prueba de ello son las resoluciones de las salas superiores que revocan la decisión de primera instancia. Debemos tener presente y dejar en claro que la prisión preventiva debe ser una medida que se dicte de manera excepcional.

\section{CONCLUSIONES}

1. Es indudable que la aplicación de la medida cautelar personal llamada prisión preventiva es necesaria e importante en los casos en que existen y se cumplen los supuestos regulados por ley para su imposición; de ello no tenemos la menor duda.

2. La aplicación de la prisión preventiva como respuesta al clamor popular se desvía completamente de la naturaleza jurídica de la imposición de tal medida. Pretender hacer creer a la sociedad que por el hecho de que las autoridades dicten medidas de prisión preventiva están garantizando nuestra seguridad es un grave error, pues se impone tal medida sin comprobar objetivamente los requisitos exigidos por ley. 
3. Los requerimientos de prisión preventiva deben formularse en la medida que exista convicción y elementos de prueba suficientes que permitan confirmar los supuestos previstos en la ley y, a su vez, otorgarse si estos se cumplen.

4. Es evidente que ha existido un exceso al dictar la medida y esto ha sido objeto de corrección por la Sala Superior en el caso de las apelaciones, e inclusive por el Tribunal Constitucional cuando la medida era consecuencia de la violación o no respeto de las garantías constitucionales.

5. Tal y conforme lo reitero cada vez que me ocupo de este tema, el problema persiste porque en estos tiempos ni el derecho penal es la última ratio, ni la prisión preventiva una medida de excepción. En la medida en que no se corrija esa situación, seguiremos observando en muchos casos situaciones que privan injustamente de su libertad a personas en cuyos casos no existen los elementos de prueba suficientes para siquiera acusarlas de la comisión de un hecho delictivo.

\section{REFERENCIAS}

LP. Pasión por el Derecho. (28 de septiembre del 2019). Fiscal ensaya 18 tipos de arraigo de sujeción en la prisión preventiva. https:///pderecho.pe/fiscal-ensaya-18-tiposde-arraigo-de-sujecion-en-la-prision-preventiva

Nuevo Código Procesal Penal. Decreto Legislativo 957 del 2004. 22 de julio del 2004 (Perú). Edición oficial del 2020. https://cdn.www.gob.pe/uploads/document/ file/1542316/Libro\%20Procesal\%20Penal.pdf

Primera Sala Penal de Apelaciones Nacional Permanente Especializada en Delitos de Corrupción de Funcionarios. Expediente 00036-2017-48-5002-JR-PE-03. Sentencia del 30 de abril del 2020. https://img.lpderecho.pe/wp-content/ uploads/2020/04/Exp.36-2017-48-LP.pdf

XI Pleno Jurisdiccional de las Salas Penales Permanente, Transitoria y Especial. Acuerdo Plenario 01-2019/C J-116 [Corte Suprema de Justicia]. 10 de septiembre del 2019. https://static.legis.pe/wp-content/uploads/2019/10/Acuerdo-plenario-1-2019CIJ-116-Legis.pe_.pdf.pdf 
